\title{
MODERN TRENDS OF DEVELOPMENT OF THE GLOBAL MARKET OF TRUST MANAGEMENT SERVICES
}

\author{
Djakona Valentina ${ }^{1}$, Perminov Stanislav ${ }^{2}$

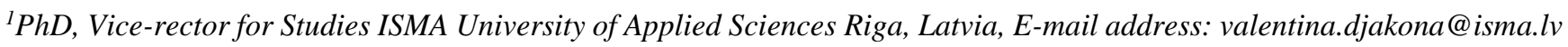 \\ ${ }^{2}$ Postgraduate student ISMA University of Applied Sciences, Riga, Latvia, E-mail address: psb70@ protonmail.com
}

Received 1005 2021; Accepted 12052021

\begin{abstract}
The article is devoted to the problems of development of trust management services in the banking system. The practice of trust management, its legal regulation has its own characteristics at the national and international levels. In world practice, this service is constantly evolving and is increasingly becoming an important integral part of banking in different countries and regions. The purpose of the article is an analytical characteristic of the development of modern trends in the global market for trust management of assets services. The article shows the dynamics of the development of the trust management market at the global level, reveals regional trends, features of the development of certain forms of trust management.
\end{abstract}

Keywords: trust, trust management, assets.

JEL Codes: F36, G11, G15, G21.

\section{Introduction}

The modern global economy is rapidly developing under the influence of such factors as the spread of ICT, an increase in security risks, a pandemic, etc. Banking in such conditions is also transforming, looking for new areas, mechanisms and tools. One of the important areas of modern banking is trust management of assets. There are certain nuances in understanding the essence of this concept and in the formulation (Wealth management, Private banking), as well as in the degree of development of trust management, its various forms of manifestation in the legal and economic sphere in different countries. Nevertheless, the dynamics of modern development testifies to the trends in the formation of the global market for trust management services, which is characterized by certain features and trends. It is these circumstances that determine the special relevance of the study of the peculiarities of the development of the remote control market at the global, international and regional levels. The opportunities and prospects for the development of trust management services, taking into account both local mental and socio-economic characteristics, and global trends, are of obvious interest for each country and each bank.

\section{The purpose of this research}

Purpose of this study is analytical characteristics of the development of the global market for trust management services.

Research object is a global market for banking services.

Research subject - trends of the development of trust management services at the global level.

Copyright (C) 2021 Author(s), published by Vytautas Magnus University. This is an open access article distributed under the terms of the Creative Commons Attribution Non-Commercial 4.0 (CC BY-NC 4.0) license, which permits unrestricted use, distribution, and reproduction in any medium provided the original author and source are credited. The material cannot be used for commercial purposes. 


\section{Data and methodology}

The content of the study, scientific conclusions, conclusions and recommendations are based on the wide application of the systemsanalytical approach to the study of processes. The proposed work demonstrates the use of the following methods: a review of scientific literature and world analytics, a quantitative empirical study in order to determine global trends in the development of the trust management services market in banks. The article uses the methods of descriptive statistical analysis and visualization, comparative analysis and assessment of the dynamics of key forms of development of trust management.

\section{Results}

The development of banking activities is a necessary component of the development of the economy as a whole, which necessitates the search for new opportunities to expand the range of services in the banking sector, and especially trust management services. The objective prerequisites for the development of trust management services in banking are: a permanent process of economic development, accompanied by an increase in the money supply and the need for additional credit resources; the growth of savings and savings of the population along with the formation of a middle class; a gradual increase in the share of financial assets in the structure of capital and the welfare of the population; the need to develop relatively reliable financial instruments for effective management of these assets; a sufficient level of development of the banking system and financial institutions; accumulation of experience in the field of trust management; formation of a legal framework regulating the trust management market. Trust management is a relatively new type of banking services, this is a type of economic relations in which several entities take part and involves the receipt of passive income. The development of this type of banking activity in the context of general globalization is characterized by certain trends: uneven development in some countries (and, above all, in developing countries, where these services are provided insignificantly); the formation of a global market for trust management and increased competition between regions and countries; increasing diversification of trust management services and the emergence of new innovative forms of it.

The key trends in the future development of the market and its revitalization are: an increase in the number of individual investors and an increase in mass welfare, an increase in the number of rich people, especially in the Asian region; expanding the functionality of state investment funds focused on various goals and programs; an increase in the number of individual pension savings, which will lead to the development of pension funds; an influx of so-called "old money" (money accumulated after the Second World War) that enter the market as a result of wills; activation of the Asian region in the trust management market.

It should be noted that there is a gradual increase in the number of assets under management in the market. Although during the crisis years there is a slight decrease in assets, however, this is a situational phenomenon that does not affect the general trends in the development of the market. In general, experts define the asset management market at the level of \$ 63.9 trillion. in 2014 to 101.7 trillion dollars. in 2020 , which is a growth rate of more than $6 \%$ (Table 1). 
Management Theory and Studies for Rural Business and Infrastructure Development

eISSN 2345-0355. 2021. Vol. 43. No. 4: 474-483

Article DOI: https://doi.org/10.15544/mts.2021.43

Table 1. Global asset management market, trillion dollars, 2004-2020

(Asset management..., 2020)

\begin{tabular}{|l|c|c|c|c|}
\hline \multicolumn{1}{|c|}{ Products } & $\mathbf{2 0 0 4}$ & $\mathbf{2 0 0 7}$ & $\mathbf{2 0 1 2}$ & $\mathbf{2 0 2 0}$ (estimated) \\
\hline Global asset market under management & 37,3 & 59,4 & 63,9 & 101,7 \\
\hline - of which mutual funds & 16.1 & 25,4 & 27,0 & 41,2 \\
\hline - active investments & 15,1 & 23,3 & 23,6 & 30,8 \\
\hline - passive investments & 1,0 & 2,0 & 3,4 & 10,5 \\
\hline - of which mandates & 18,7 & 28,8 & 30,4 & 47,5 \\
\hline - active investments & 17,6 & 26,5 & 26,6 & 35,3 \\
\hline - passive investments & 1,2 & 2,3 & 3,9 & 12,2 \\
\hline - alternative investment & 2,5 & 5,3 & 6,4 & 13,0 \\
\hline
\end{tabular}

Based on the data in Table 1, we can conclude that the most popular is active participation in investment processes, as well as such a form as mandates, which in fact represent certain assets under management, focused on specific goals.
In general, the global asset management market demonstrates growth both as a whole and its individual components: pension funds, individual and government investment accounts (Table 2).

Table 2. Client structure of the asset management market, trillion dollars, 2005-2020 (Asset management..., 2020)

\begin{tabular}{|l|c|c|c|c|}
\hline \multicolumn{1}{|c|}{ Clients } & $\mathbf{2 0 0 4}$ & $\mathbf{2 0 0 7}$ & $\mathbf{2 0 1 2}$ & $\mathbf{2 0 2 0}$ \\
\hline Pension funds & 21,3 & 29,4 & 33,9 & 56,5 \\
\hline Insurance companies & 17,7 & 21,2 & 24,1 & 35,1 \\
\hline Sovereign Wealth Funds (SWF) & 1,4 & 3,3 & 5,2 & 8,9 \\
\hline $\begin{array}{l}\text { Individual accounts (High-net-worth } \\
\text { individual, HNWI) }\end{array}$ & 37,9 & 50,1 & 52,4 & 76,9 \\
\hline Individual accounts (Mass affluent) & 42,1 & 55,8 & 59,5 & 100,4 \\
\hline
\end{tabular}

In the modern globalized world, the interdependence of economies is increasing, which in turn affects the formation of a market for trust services or assets under management. For example, changes in the size and composition of the GDP of the United States of America can influence changes in the structure and number of assets under management in the Asian region. PwC research results show the relationship between the development of the asset management market and general economic factors (Asset management..., 2020).

Among the key trends in the development of the asset management market, the more active development of the regional Asian market stands out, the growth rate of which is outstripping global indicators. At the same time, the main assets are located in North America and Europe, and if in 2010 the weight of the region in the MSCI World Index was only 9\% (part of the global GDP is 18\%), then by 2020 part of GDP is up to $25 \%$, which in turn is reflected in the MSCI index and, accordingly, will contribute to further capital inflows to the region.

According to the results of the $\mathrm{PwC}$ research, more than $40 \%$ of managers (trustees, asset managers) consider the Asian region as one of the most promising in the coming years [4]. In addition, new players appear on the Asian market itself, which can compete with classical players from developed countries (Fig. 1). 


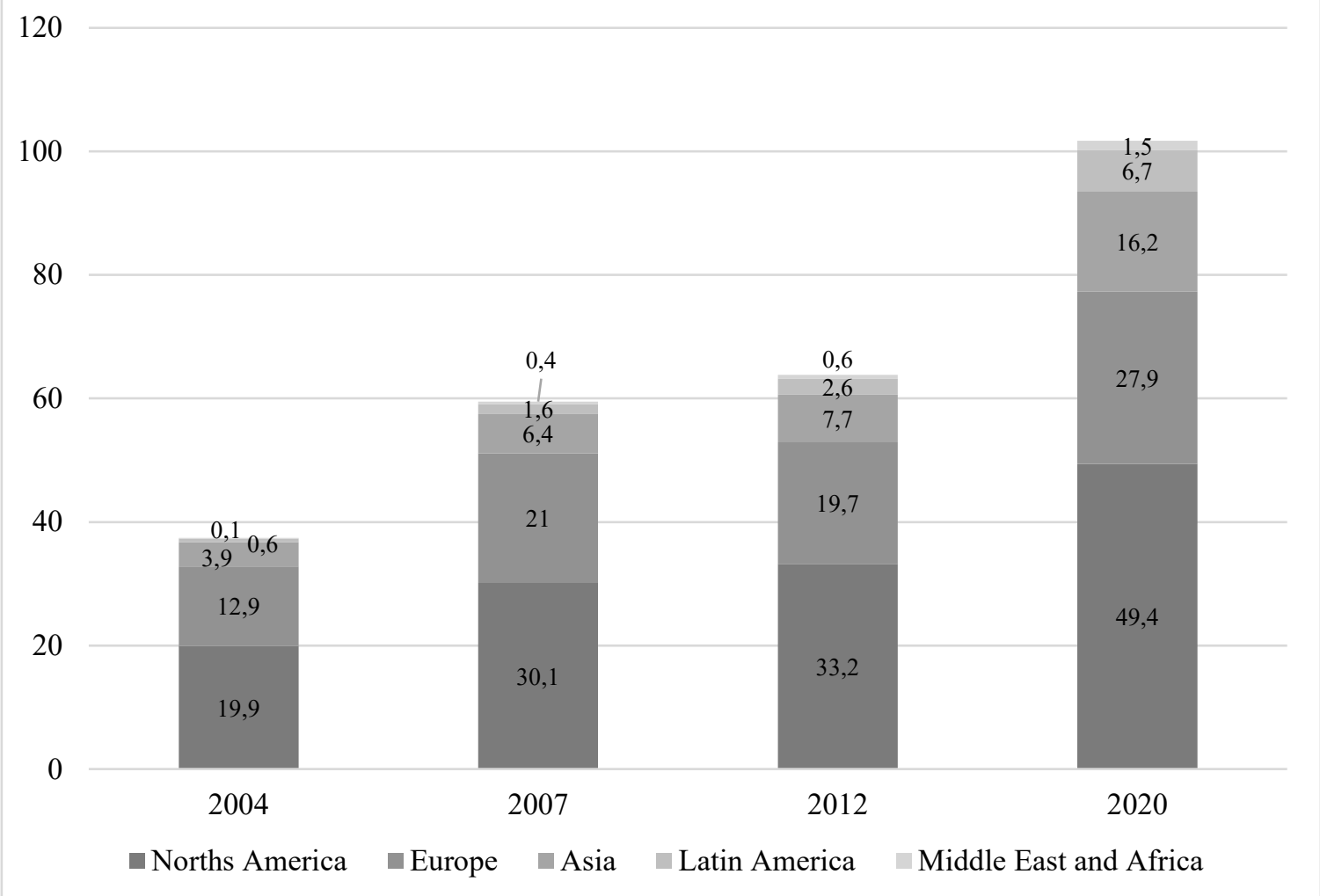

Figure 1. Geographic structure of the asset management market, trillion dollars (Asset management..., 2020)

And although this market on a global scale is still being formed, its growth rates are quite high. Thus, the North American market for the analyzed period increased by $5.1 \%$, Asia $-9.8 \%$, Latin America - 12.5\%. At the same time, Europe is showing a modest $4.4 \%$ growth. On the one hand, this testifies to the dynamic development of developing countries, on the other, to a slowdown in growth and the depletion of resources for development in developed countries. Among the geographic regions, the North American market will continue to dominate, which can be explained by both the level of market development and the active growth of medium-sized companies and the formation of an active market for shares of the first and second echelons, and the development of the blue-chip market. However, until 2030, the highest growth rates will be demonstrated by the Asia-Pacific region. (Global..., 2020). The growth and stability of the North American market is ensured by the work of global bluechip giants, including IBM Corp., Microsoft Corp, Oracle Corp, SAP SE, Infor, Sunflower systems и АВВ Group (Global..., 2019).

At the same time, not only clients from the HNWI segment are actively entering the market, but also clients with an upper middle income level and especially active in the Asian market. If for the first segment the growth is $4.9 \%$, then the middle class demonstrates $6.8 \%$, in addition, in the North American market this growth is $10 \%$, then the Asian segment demonstrates a record 30\% (Asset management..., 2020). These trends support forecasts that the middle class will grow by $180 \%$ by 2040 and will be concentrated in developing countries (OECD, 2010).

Among the trends in the development of the asset management market, we also highlight the active development of sovereign funds (state investment funds) in world capital. Such funds 


\section{sciendo}

Management Theory and Studies for Rural Business and Infrastructure Development

eISSN 2345-0355. 2021. Vol. 43. No. 4: 474-483

Article DOI: https://doi.org/10.15544/mts.2021.43

can be used as stabilization funds in the event of macroeconomic fluctuations, as a way to accumulate resources and invest them in socioeconomic projects. Global imbalances lead to the need to form such funds for the accumulation of financial resources that can be used in the economy. Such imbalances are caused by fluctuations in the prices of raw materials (in particular, for oil and oil products). The creation of such funds led to the fact that they began to play a large role in the asset management market. If in 2014 such funds amounted to about 5 trillion dollars, then in 2020 they increased to almost 9 trillion. Moreover, the most active growth of such assets can be observed in the Asia-Pacific region and the Middle East.

A fairly significant part of the asset management market is occupied by pension funds, which accumulated about $\$ 57$ trillion in 2020. On average, the annual growth is over $6 \%$, which is a fairly high figure. The growth of such assets is especially active in developing countries, which have good GDP growth rates. The most active growth is shown by the markets of Latin America and the Asia-Pacific region, with growth rates of $9 \%$ each, which is an indicator higher than in the world as a whole. It should be noted, however, that their share in the global volume of these regions is not too high; the classically leaders are North America and Europe with the highest rates of pension savings (Asset management..., 2020).

The most attractive instrument for trust management are mutual funds and mandates, which on average give more than 5\% profitability. Mutual funds are also increasing due to the growth in the number and well-being of individual investors, who are also focused on the formation of pension funds. However, the growth of mandates can also be ensured by increasing the number of institutional investors (pension funds, state investment funds), etc. (fig. 2).

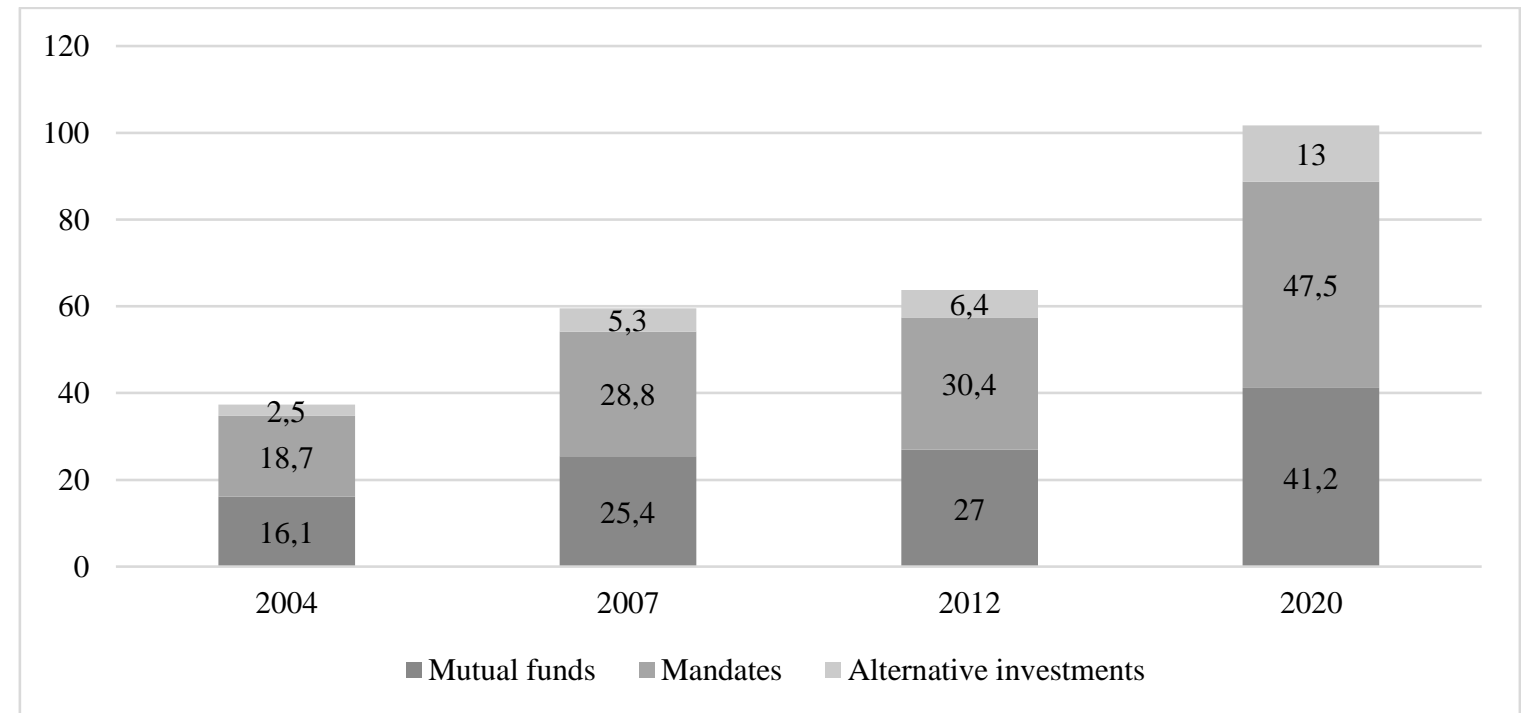

Figure 2. Global market for asset management services by instrument, trillion dollars (Asset management..., 2020)

In general, the growth of mutual investment funds is observed at $5.4 \%$, mandates by $5.7 \%$, the largest increase is demonstrated by alternative investment $-9.3 \%$.
In general, the key drivers of growth in the market for trust and corporate services are the growth in the number of sovereign investors and their prosperity, as well as an increase in global 
GDP per capita. The key players in the asset management market are companies such as Intertrust, JTC Group, SGG, TMF Group (Global trust..., 2020a).

Market development challenges and constraints include: declining confidence, ambiguity across jurisdictions, the COVID-19 pandemic, rising unemployment, situational declines in income, increasing sovereign investors, and expanding the capacity and activity of pension funds. In general, this negatively affected the development of the asset management market in 2020 and similar trends are expected in 2021. The impossibility of conducting audits (or restrictions due to the physical closure of borders) leads to some decrease in confidence (Global trust..., 2020b).

However, global digitalization and the arrival of the Internet lead to the need for market development in terms of digital asset management and digital finance as well. This, in turn, complicates fund structures and forms both new markets and new segments. On the one hand, these are new opportunities, on the other, new risks associated with information leakage and cyber threats. Certain risks are also borne by the withdrawal of Great Britain from the members of the European Union (Global trust..., 2020b).

It should be noted that forecasts for the development of the capital management market by 2030 indicate the possibility of making a profit of up to 26 billion dollars. (in 2019 it was 5.5 billion dollars) with an average annual growth rate of more than $17 \%$. As noted, the market is actively growing and globalizing, and the number of individual investors is increasing. However, corporate clients also see their advantages in such a market, aiming to reduce operating costs, increase return on investment and reduce overall costs. The COVID-19 pandemic has slowed market growth somewhat, due to a decrease in international business activity and the blocking of some transactions or activities. This, on the one hand, had a negative impact on the financial market, but on the other hand, it has actualized the issue of finding additional income for the vacated assets. The asset management market is dominated by corporate capital and this trend is expected to continue until 2030. High-tech sectors, telecommunications, healthcare, which are dynamically developing and with a high turnover of capital, are identified as particularly attractive for investments. The dynamism of the development of this segment, a high level of average annual growth is formed due to a large number of startups, and the growth of the healthcare segment is also predicted (especially in connection with the global pandemic) (Global..., 2020).

In the period by 2025 , the growth rate of the asset management market will remain at the level of $11 \%$, however, such factors as lack of awareness and low level of financial literacy in certain regions also affect the growth of the market. The introduction of cloud technologies and global technologization are becoming a prerequisite for the development of the market. Vertically integrated structures are being formed in the market, which makes it possible to single out global players, while simultaneously forming regional markets (Global..., 2019).

It is worth paying special attention to trusts and various funds that manage certain types of assets. Major players in the trust market are United Way Worldwide, Feeding America, Task Force for Global Health, Salvation Army, American National Red Cross, St. Jude Children's Research Hospital, Americares Foundation, Food for the Poor, United States Found for UNICEF and MAP International (Global trust..., 2020).

According to Research \& Markets, the global trust market in 2019 was $\$ 161.9$ billion, in 2020 - $\$ 163.1$ billion, providing an average annual growth (CAGR) of $0.73 \%$ (Global trust..., 2020). Among the reasons for the low growth are the global pandemic, social distancing, reduced market and business activity, and a remote robot that is holding back market development. However, the company predicts that the market will recover by 2023 and will total \$ 197 billion, providing a 6.5\% CAGR. 
In this market, the most active market is the North American market, and the fastest growing is the Asia-Pacific. The limiting factors for this market are the active use of trusts to cover up illegal or illegal activities, so in 2020, the New Vision study mentioned the illegal operation of more than 200 refugee companies in Uganda, operating without the necessary documents, memoranda, etc. Of the total number of trust companies, only 69 companies functioned legally and with a full package of documents, operating with assets.

The trust market is a specific segment, focusing on philanthropy and forming a separate market (or segment) for donors. The key aspects of the activities of such organizations are focused on combating global problems, poverty, climate change, and ensuring the implementation of the UN's global goals. According to research by the National Philanthropic Trust (NPT), about $90 \%$ of highincome households are involved in charity work and form trusts. So, in 2019 alone, 449.64 billion dollars were donated to charity, with an increase of $5.1 \%$ compared to 2018 , and about $70 \%$ of the total financial assets were formed at the expense of private receipts, and only $17 \%$ from various funds. As in corporate asset management, one of the growth factors of this market segment is an increase in the general welfare of the population (Global trust..., 2020).

Among the instruments or objects of management, there is also a custodian bank (or company), which includes specialized financial institutions dealing only with the management of financial assets, without using other instruments of functioning on the market (retail banking, servicing individuals or legal entities, ATM service, etc.). The key functions of custodian banks are implemented in:

- storage of securities or assets (stocks, bonds, precious metals, currency);

- to carry out settlements on securities under management;

- accumulation of income from assets (dividends, interest payments or payments of another plan);

- management of assets under management;

- provision of key information on securities and powers of attorney;

- registration of accounts (cash, bank, etc.), carrying out cash or foreign exchange transactions;

- maintenance of mutual funds (accounting, administration, legal support, tax clearance) (Custodian bank, 2020).

The custodian bank does not become the owner of the securities, but only takes part in the chain of generating additional income for the beneficiary. In different jurisdictions, the functions and capabilities of custodian banks may differ slightly, for example, in the UK jurisdiction (Great Britain, Australia, South Africa, etc.), such banks are used to identify shareholders or ultimate owners of securities. Such a chain mainly contains assets under the management of larger players, including individual banks, insurance companies, mutual funds, hedge funds, pension funds, etc.

Significant amounts of assets of various beneficiaries are managed and held in custody banks. Thus, only the top five custodian banks manage more than $\$ 100$ trillion (table 3). 
Table 3. Largest global custodian banks, 2019

(Assets under..., 2019)

\begin{tabular}{|l|l|c|c|}
\hline \multicolumn{1}{|c|}{ Rank } & \multicolumn{1}{|c|}{ Bank } & Country & $\begin{array}{c}\text { Amount under } \\
\text { management, trillion }\end{array}$ \\
\hline 1 & The Bank of New York Mellon & USA & 25,08 \\
\hline 2 & State Street & USA & 21,35 \\
\hline 3 & JPMorgan Chase & USA & 20,5 \\
\hline 4 & Citi & USA & 13,0 \\
\hline 5 & BNP Paribas & France & 11,8 \\
\hline 6 & HSBC & United Kingdom & 8,5 \\
\hline 7 & MUFG & Japan & 6,3 \\
\hline
\end{tabular}

As you can see, the preservation of custodian banks is the amount that exceeds the budgets of individual countries by several times, which indicates the popularity of the service of preserving and managing assets. Most of the global custodian banks are located in highly developed countries with stable economic development. However, it is worth noting that not all of the assets under management are under active trust. So, for example, in the second quarter of 2020 , more than $\$ 2$ trillion were under management, and \$38.6 trillion under preservation (The bank of..., 2020; About BNY..., 2020).

In each region, a main custodian bank is distinguished: in America - Bank of New York Mellon, in the Asia-Pacific region - HSBC, in Europe, the Middle East and Africa - JP Morgan (Global custody..., 2019).

It is worth noting that most of the assets to be preserved and managed on behalf of the beneficiary in custodian banks are pension funds of various forms (IRA, Roth IRA, SEP IRA or $401 \mathrm{k}$ ), which are serviced by banks within the framework of management (determining the need and number of transactions, servicing accounts, investment). It should be noted that pension savings are also managed in two forms: preservation of securities and management (including through alternative investments, which consist in investing in real estate, precious metals, mortgage lending, shares, licenses and other securities, definition in shares funds).

Custodians and managers of mutual funds act as service agents for such a fund, performing accounting, administration or registration of such funds, keeping records of key shareholders, paying dividends or interest in profits, their accounting and redistribution.

\section{Conclusions}

Thus, we can note that the trust management of asset market is in constant growth and the search for new tools and mechanisms for its development. In general, trust management is formed in a separate market, and not as a segment of banking or insurance activities. The volume of the global trust management services market is growing dynamically. The main share of trust management services in the world is represented by the countries of North America and Europe, at the same time, the market of the countries of the Asia-Pacific region is growing rapidly. The trust management services market is also characterized by constant diversification processes: new financial products and instruments appear. 


\section{sciendo}

Management Theory and Studies for Rural Business and Infrastructure Development

eISSN 2345-0355. 2021. Vol. 43. No. 4: 474-483

Article DOI: https://doi.org/10.15544/mts.2021.43

\section{References}

About BNY Mellon. www.bnymellon.com. Retrieved March 8, 2021.

Asset Management 2020 A Brave New World. https://www.pwc.com/gx/en/asset-management/publications/pdfs/pwcasset-management-2020-a-brave-new-world-final.pdf

$\begin{array}{lllll}\text { Assets } & \text { under } & \text { Custody. } & \text { June } & 15,\end{array}$

https://web.archive.org/web/20181215173638/https://www.globalcustody.net/asset_tables/custody_assets_worldwide/ from the original on December 15, 2018. Retrieved June 15, 2019.

Custodian_bank. https://en.wikipedia.org/wiki/Custodian_bank

Global \$25.9 Bn Enterprise Asset Management Market to 2030. 2020. https://www.globenewswire.com/newsrelease/2020/11/06/2122033/0/en/Global-25-9-Bn-Enterprise-Asset-Management-Market-to-

2030.html\#: :text=The\%20global\%20enterprise $\% 20$ asset $\% 20$ management,reducing $\% 20$ operational $\% 20$ expenses $\% 20$ in $\% 2$

Ocompanies

Global Custody Survey 2019. July 4, 2019. Retrieved July 4, 2019

Global Enterprise Asset Management 2019. https://www.researchandmarkets.com/reports/4901058/global-enterprise-asset-management-market-2019\#rela1-5184643

Global Trust and Corporate Service Market: Size and Forecasts with Impact Analysis of COVID-19 (2020-2024). 2020a. https://www.researchandmarkets.com/reports/5130255/global-trust-and-corporate-service-market-size

Global Trust and Foundations Market Report 2020: 2015-2019, 2023F, 2025F, 2030F. $2020 \mathrm{~b}$. https://www.prnewswire.com/news-releases/global-trust-and-foundations-market-report-2020-2015-2019-2023f-2025f-

2030f-301209451.html\#: :text=The\%20global\%20trusts\%20and\%20foundations,(CAGR)\%20of\%200.73\%25.

OECD 2010, Homi Kharas, The Emerging Middle Class in Developing Countries.

The Bank of New York Mellon Corporation 2018 Annual Report. U.S. Securities and Exchange Commission. Retrieved March 23, 2019. 